\title{
Nutrition and lifestyle in patients pharmacologically treated due to hypertension
}

\author{
Mirosław Jarosz ${ }^{1}$, Diana Wolańska ${ }^{2}$, Hanna Stolińska ${ }^{1}$, \\ Wioleta Respondek ${ }^{1}$, Longina Kłosiewicz-Latoszek ${ }^{2}$ \\ ${ }^{1}$ Department of Nutrition and Dietetics with Clinic of Metabolic Diseases and Gastroenterology, \\ National Food and Nutrition Institute, Warsaw, Poland \\ ${ }^{2}$ Department of Prevention of Diet-related Diseases with Outpatient Clinic of Metabolic Diseases, \\ National Food and Nutrition Institute, Warsaw, Poland
}

\begin{abstract}
Background: Proper nutrition and physical activity are together an important way of non-pharmacological treatment of arterial hypertension. The aim of the study was to answer the question whether patients with hypertension use non-pharmacological methods of hypertension treatment.
\end{abstract}

Methods: The study included a group of 280 patients aged 18-85, suffering from hypertension. In the study, 10 nutritional and non-nutritional factors affecting the treatment of hypertension were analyzed. Data regarding the diet were collected by a method of 24-h recall. Basic anthropometric measurements (body weight, body height, waist and hip circumference) were taken, as well as threefold measurement of blood pressure. The data were statistically analyzed. Results: The average value of blood pressure was $131.2 \pm 15.5 / 82.9 \pm 10.5 \mathrm{~mm} \mathrm{Hg}$. Approximately $90 \%$ of the respondents had abnormal body weight, i.e. excessive weight or obesity. Abdominal obesity according to waist hip ratio assessment was diagnosed in $87 \%$ of women and $66 \%$ of men; according to the measurement of waist circumference, it was diagnosed in 140 (81\%) women and 88 (81\%) men. Among the ingredients with antihypertensive effect, the sodium intake was $4,417.8 \pm 2,052.7 \mathrm{mg} / \mathrm{d}$, which when converted to salt is on average $11 \mathrm{~g} / \mathrm{d}$, potassium: $3,808.5 \pm 1,265.7 \mathrm{mg} /$, calcium: $724.6 \pm 413.7 \mathrm{mg} /$, and magnesium: $383.9 \pm$ $\pm 139.3 \mathrm{mg} / \mathrm{d}$. One in 5 (18\%) people declared smoking. Only 5\% of subjects reported high level of physical activity.

Conclusions: In persons with diagnosed hypertension, vast majority of patients did not implement non-pharmacological hypertension treatment. (Cardiol J 2016; 23, 5: 491-496)

Key words: hypertension, obesity, salt, diet, lifestyle

\section{Introduction}

Hypertension has been a serious medical problem for many years. It is estimated that the frequency of the prevalence of hypertension in the general population is approx. $30-45 \%$, but it signifi- cantly increases with age [1]. In the NATPOL study conducted in 2011, it was demonstrated that the number of people suffering from hypertension increased during the last 10 years by $2 \%$ on average, and currently approx. $32 \%$ of adult Poles suffers from it (10.5 million patients, including 9.5 million

Address for correspondence: Prof. Mirosław Jarosz, MD, PhD, Department of Nutrition and Dietetic with Clinic of Metabolic Diseases and Gastroenterology, National Food and Nutrition Institute, ul. Powsińska 61/63, 02-903 Warszawa, Poland, tel: +48 22 550-96-77, fax: +48 22 842-11-03, e-mail: jarosz@izz.waw.pl 
aged $18-79$ and almost 1 million patients above 80 ) $[2,3]$. In the WOBASZ study, the frequency of the prevalence of hypertension was $36 \%$, including $33 \%$ in women and $42 \%$ in men. In POLSENIOR study, the prevalence of hypertension in the sample of Poles $(\mathrm{n}=4,929)$ over 64 years was $76 \%(72 \%$ in men, $78 \%$ in women) [4].

Hypertension is a major risk factor for cardiovascular disease, which in turn is the leading cause of death in industrialized countries. Hypertension very often co-occurs with obesity, diabetes, and lipid abnormalities, which greatly increases the risk of cardiovascular diseases. It is the leading cause of heart attacks and strokes, as well as heart and kidney failure.

It has been demonstrated that a properly conditioned modification of lifestyle has equivalent antihypertensive effect as the use of 1 antihypertensive medicine [5]. The changes in lifestyle also contribute to the control of other cardiovascular risk factors resulting from the co-occurrence of diet-related diseases. The main recommended lifestyle changes that affect blood pressure (BP) include: reducing salt intake and alcohol consumption, high intake of fruit, vegetables and calcium and diet consisting of low-fat products, especially of animal origin, maintaining appropriate body weight or its reduction in case of excessive weight/obesity, regular physical activity, smoking cessation [1].

Hypertension and its complications (e.g. strokes, heart attacks) are a serious public health problem and economic burden to the Polish health care system. In order to reduce the risk of complications and costs, non-pharmacological methods of hypertension treatment are important. Therefore, the authors decided to analyze whether patients with hypertension follow (and to what extent) the essential recommendations of non-pharmacological treatment of this disease.

The aim of the study was to answer the question whether patients with hypertension use non-pharmacological methods of hypertension treatment.

\section{Methods}

The study was conducted at the National Food and Nutrition Institute from October 2010 to November 2011 in a group of 280 subjects aged 18-85. The study included patients referred to the Outpatient Clinic of Metabolic Diseases and Clinic of Metabolic Diseases and Gastroenterology of the National Food and Nutrition Institute with diagnosed hypertension and who took an- tihypertensive medicines on a permanent basis. The respondents gave their written consent to participate in the study.

In the study group, on the basis of the author's questionnaire, data were collected on the prevalence of diseases including hypertension, and type of pharmacotherapy chosen as treatment. Data on lifestyle factors that affect BP, including physical activity and smoking and alcohol consumption. Data on nutritional habits were collected by 24 -h recall, on the basis of which the daily food ration was estimated using the "Album of photos of products and dishes" [6] and its nutritional value was calculated using a computer program Diet 5.0.

In the study, 10 nutritional and non-nutritional factors, which affect the hypertension treatment were analyzed: intake of sodium, potassium, calcium, magnesium, adding salt to meals, drugs, intake of alcohol and smoking, prevalence of excessive weight and obesity, as well as physical activity. The level of physical activity was evaluated according to the following criteria: 1) Low physical activity - it refers to a person whose daily activities require no effort. The person moves mainly by car, and does not practice any sport regularly. The person spends most of the time sitting or standing. 2) Moderate physical activity - a person who has sedentary work, but regularly spends a certain amount of time on moderate or intensive physical activity. 3) High physical activity - a person performing intense physical work regularly, a few hours a day.

Every subject had threefold BP measurement according to standard guidelines of the European Society of Hypertension (ESH) with the use of Omron MT-10 IT (Omron, Hoofddorp, The Netherlands). From the obtained values, the average value of $\mathrm{BP}$ was calculated [7].

On the basis of anthropometric measurements (body weight and height), the nutritional status was assessed using weight-height body mass index (BMI), calculated according to the formula: $\mathrm{BMI}=$ body weight $(\mathrm{kg}) /$ body height $\left(\mathrm{m}^{2}\right)$. According to World Health Organization (WHO) guidelines [8], excessive weight was recognized at BMI values $25-29.9 \mathrm{~kg} / \mathrm{m}^{2}$ and obesity when BMI was $\geq 30 \mathrm{~kg} /$ $/ \mathrm{m}^{2}$ [8]. Using the measurements of waist and hip circumference, waist hip ratio (WHR) was calculated defining the type of obesity. According to WHO guidelines it was assumed that the WHR value lower than 0.8 in women and lower than 1.0 in men indicates gynoid obesity (gluteal-femoral), whereas the WHR value higher than 0.8 in women and higher than 1.0 in men is determined as abdominal obesity. Abdominal obesity was also evaluated on 
the basis of waist circumference measurement and the criteria adopted for the diagnosis of this anomaly according to National Cholesterol Education Program Adult Treatment Panel III (NCEP-ATP III) - waist circumference $\geq 102 \mathrm{~cm}$ in men and $\geq 88 \mathrm{~cm}$ in non-pregnant women [9] The data were statistically analyzed using Statistica 10.0 program.

\section{Results}

\section{Characteristics of the study group}

The study group consisted of 280 patients, including 171 women and 109 men, respectively $61 \%$ and $39 \%$ of the study group. The average age was $55.0 \pm 12.1$ years. The subjects were of secondary education (47\%) and higher education (35\%). Most patients (73\%) were individuals who retired/retired or performed a sedentary job. Work requiring physical effort was $26 \%$ of respondents.

All subjects who participated in the study $(\mathrm{n}=280)$ suffered from hypertension and took antihypertensive medicines on a permanent basis. These were mainly beta-blockers $-36 \%$ of respondents, comparable drugs from the group of angiotensin-converting enzyme (ACE) inhibitors and diuretics (22\% and 20\%), medicines in the angiotensin II receptor antagonists in $12 \%$ of patients, medicines calcium channel blockers $-10 \%$ of patients. Taking medicines for hypertension lasted for a period of $11.3 \pm 8.7$ years on average. The average value of BP in the whole group was $131.2 \pm 15.5 / 82.9 \pm 10.5 \mathrm{~mm} \mathrm{Hg}$. Normal values of $\mathrm{BP}$ were encountered in $20 \%$ of respondents. Additional diseases were lipid disorders in $78 \%$ of patients, type II diabetes in $14 \%$, and gout in $12 \%$.

\section{The results of anthropometric test}

Average body weight was $96.5 \pm 22.8 \mathrm{~kg}(89.9 \pm$ $\pm 21.3 \mathrm{~kg}$ for women and $107 \pm 21.3 \mathrm{~kg}$ for men), BMI $34.0 \pm 6.8 \mathrm{~kg} / \mathrm{m}^{2}$. Ninety percent of respondents had abnormal body weight, i.e. excessive weight or obesity. In 1 in 5 (19\%) subjects, excessive weight was diagnosed, i.e. BMI $25.0-29.9 \mathrm{~kg} / \mathrm{m}^{2}$ and in $71 \%$ it was obesity (BMI $\left.\geq 30 \mathrm{~kg} / \mathrm{m}^{2}\right)$ including morbid obesity (BMI $>40.0 \mathrm{~kg} / \mathrm{m}^{2}$ ) which was diagnosed in $18 \%$ of people.

On the basis of WHR, it has been demonstrated that among the subjects abdominal obesity prevailed. Average value of WHR was $0.87 \pm 0.06$ in women and $1.02 \pm 0.06$ in men, respectively. The problem of abdominal obesity according to WHR evaluation concerned $87 \%$ of women and $66 \%$ of men.

Abdominal obesity, classified on the basis of waist circumference above $88 \mathrm{~cm}$ in women, was observed in 140 women ( $81 \%$ ), and the average waist circumference was $104.7 \pm 15.9 \mathrm{~cm}$. Waist circumference above $102 \mathrm{~cm}$, which is the evidence of abdominal obesity, was observed in 88 (81\%) men and the average value was $116.3 \pm 15.0 \mathrm{~cm}$.

In addition to hypertension, $78 \%$ of the subjects had lipid abnormalities (increased cholesterol and triglycerides), $18 \%$ type II diabetes, and $13 \%$ gout.

\section{Nutritional factors}

The energy value of the analyzed daily food rations was on average $2146.9 \pm 844.4 \mathrm{kcal}$. In the total pool of energy, energy from protein constituted $18.2 \pm 4.9 \%$, from carbohydrates $47.7 \pm 8.9 \%$, and from fat $33.3 \pm 8.4 \%$. Protein intake averagely amounted to $94.4 \pm 37.1 \mathrm{~g}$, including $65.6 \pm 31.1 \mathrm{~g}$ of protein of animal origin and $28.7 \pm 11.2 \mathrm{~g}$ of vegetable protein. Average protein intake per $\mathrm{kg}$ body weight was $1 \mathrm{~g}$. Among the ingredients with antihypertensive effect, sodium intake was $4,417.8 \pm$ $\pm 2,052.7 \mathrm{mg} / \mathrm{d}$, which when converted to salt was on average $11 \mathrm{~g} / \mathrm{d}$, potassium: 3,808.5 $\pm 1,265.7 \mathrm{mg} / \mathrm{d}$, calcium: $724.6 \pm 413.7 \mathrm{mg} / \mathrm{d}$ and magnesium: $383.9 \pm 139.3 \mathrm{mg} / \mathrm{d}$. Every third (30\%) person in the study group added salt to ready-made meals, and the most commonly used salt was ordinary, iodized salt $(55 \%)$ or rock $(29 \%)$ salt. Only $9 \%$ of respondents chose low sodium, potassium or magnesium salt.

\section{Lifestyle factors}

Only $5 \%$ of patients declared high level of physical activity and $41 \%$ of respondents declared moderate level of physical activity. In contrast, low level of physical activity was declared by more than half of the respondents (53\%). The most often chosen form of activity was walking $-40 \%$ of the respondents.

Among the subjects, 1 in 5 (18\%) person declared smoking. These were subjects who, despite diagnosed disease, did not refrain from smoking, they smoked on average for $21.9 \pm 12.2$ years, $15.4 \pm 7.2$ cigarettes per day.

In the analysis assessing the implementation of the recommendations of non-pharmacological hypertension treatment (Table 1) [10], the intake of too high amount of sodium and low intake of potassium, calcium and magnesium with the diet was observed. In the study group, high percentage of the participants had abnormal body weight, especially abdominal obesity.

Regular alcohol consumption (at least 2-3 times a week) was declared by $17 \%$ of people. 
Table 1. Implementation of the recommendations of nutritional and lifestyle factors that affect blood pressure among people with hypertension.

\begin{tabular}{|c|c|c|c|c|c|}
\hline \multirow{2}{*}{$\begin{array}{l}\text { Modifiable nutritional } \\
\text { and lifestyle factors } \\
\text { of hypertension }\end{array}$} & \multirow[t]{2}{*}{$\begin{array}{l}\text { Desirable } \\
\text { values }\end{array}$} & \multicolumn{4}{|c|}{$\begin{array}{l}\text { The number and proportion } \\
\text { of the study population }(n=280)\end{array}$} \\
\hline & & \multicolumn{2}{|c|}{$\begin{array}{c}\text { Achieved } \\
\text { desirable values (n/\%) }\end{array}$} & \multicolumn{2}{|c|}{$\begin{array}{l}\text { Lack of achieved } \\
\text { desirable values }(n / \%)\end{array}$} \\
\hline \multicolumn{6}{|l|}{ Nourishment: } \\
\hline Sodium & $<1500 \mathrm{mg}^{*}$ & 9 & 3 & 271 & 97 \\
\hline Potassium & $>4700 \mathrm{mg}^{*}$ & 57 & 20 & 223 & 80 \\
\hline Calcium & $>1000 \mathrm{mg}^{*}$ & 56 & 20 & 224 & 80 \\
\hline Magnesium & $>320 \mathrm{mg} / 420 \mathrm{mg}^{*}$ & 147 & 53 & 133 & 47 \\
\hline Adding salt to meals & No & 196 & 70 & 84 & 30 \\
\hline Smoking & No & 231 & 82 & 49 & 18 \\
\hline Alcohol consumption & No & 233 & 83 & 47 & 17 \\
\hline Excessive weight and obesity & $\mathrm{BMI}<25 \mathrm{~kg} / \mathrm{m}^{2}$ & 29 & 10 & 251 & 90 \\
\hline Abdominal obesity & $\begin{array}{l}\text { WHR: women }<0.8 \\
\text { men: }<1.0\end{array}$ & 49 & 17 & 231 & 83 \\
\hline Physical activity & Moderate and high & 130 & 46 & 150 & 54 \\
\hline
\end{tabular}

Data are presented as numbers and percentages; BMI — body mass index, WHR — waist to hip ratio; *Jarosz M. ed., 2012 [10]

They were mostly men $-86 \%$ of respondents. The most popular drink was beer $-60 \%$ of subjects who consume alcohol regularly, and wine $-34 \%$ of respondents. The others $(83 \%)$ drank alcohol occasionally (not more than 1-2 times a month or less), or did not consume alcohol at all.

\section{Discussion}

The scientific literature, both domestic and foreign, does not include analyses concerning the application of the recommendations of a healthy lifestyle (nutrition and physical activity) by persons with diagnosed hypertension. Only the analyses discussing the impact of individual elements of lifestyle, including diet, on BP are available.

In the analysis of own research it was demonstrated that every fifth person had excessive weight and $71 \%$ had obesity, including morbid obesity in $18 \%$ of people.

The problem of abdominal obesity, according to WHR evaluation, concerned $87 \%$ of women and $66 \%$ of men, while according to waist circumference criterion it occurred in 140 (81\%) women and $88(81 \%)$ men. Such a high percentage of people with abnormal body weight, especially abdominal obesity, is one of the most important factors affecting the development of hypertension.

The findings of the studies suggest that body weight reduction is conducive to lowering BP.
A meta-analysis of 25 studies showed an average reduction of systolic $\mathrm{BP}$ (SBP) and diastolic BP (DBP) by 4.4 and $3.6 \mathrm{~mm} \mathrm{Hg}$ with each $5 \mathrm{~kg}$ of body weight loss [11].

In the analysis of the Korea National Health and Nutrition Examination Survey, it was demonstrated that individuals with sarcopenic obesity (loss of muscle tissue and the excessive growth of body fat) have approx. $12 \mathrm{~mm} \mathrm{Hg}$ higher SBP and $5 \mathrm{~mm}$ higher $\mathrm{Hg} \mathrm{DBP}$ than people with simple obesity [12].

In the studies by Despres at al. [13], evaluating the relationship between the content of body fat and the values of BP, it was observed that the amount of subcutaneous fat and its percentage content is significantly correlated with DBP $(\mathrm{r}=0.37, \mathrm{p}<0.0005)$ and $\mathrm{SBP}(\mathrm{r}=0.29, \mathrm{p}<0.01)$. Other factors contributing to $\mathrm{BP}$ were age and, in men, alcohol consumption.

In our study, lack of physical activity or its low level was declared by $53 \%$ of respondents, and only $5 \%$ declared high level of physical activity.

In a recent meta-analysis of randomized controlled clinical trials, it was concluded that dynamic, aerobic endurance training reduces SBP and DBP at rest by $3.0 / 2.4 \mathrm{~mm} \mathrm{Hg}$ and the average pressure throughout the day in ambulatory monitoring by $3.3 / 35 \mathrm{~mm} \mathrm{Hg}$. The reduction of SBP at rest was higher in patients with hypertension $(-6.9$ / $/-4.9 \mathrm{~mm} \mathrm{Hg}$ ) than in patients with normal BP 
$(-1.9 /-1.6 \mathrm{~mm} \mathrm{Hg})$. Even moderate physical activity lowered BP [14].

Among the study group, every fifth (18\%) person declared smoking. These were the subjects who, despite the diagnosed disease, did not refrain from smoking, and smoked on average for $21.9 \pm$ \pm 12.2 years, $15.4 \pm 7.2$ cigarettes per day.

Wanshu et al. [15], while evaluating 27,789 volunteers of the Chinese population, demonstrated that the common prevalence of excessive weight and smoking causes a 4.49 times greater risk of hypertension than a single factor [15].

In the 7-year study (2003-2010), where 297 healthy adults were observed, it was shown that over this time the main reason for the development of hypertension in $23.6 \%$ of subjects was the prevalence of abdominal obesity and smoking [16].

In another study, the strength of the main risk factors of the development of hypertension was determined - origin, nutritional habits, alcohol consumption, smoking, stress level and medical history. It has been demonstrated that among women high BP was significantly dependent on the age $(\mathrm{U}=10,513.5 ; \mathrm{z}=-5.117), \mathrm{BMI}(\mathrm{U}=9,635$; $z=-5.832)$, WHR $(U=12,738 ; z=-2.888)$ and level of cholesterol $(U=2,827.5 ; z=-2268)$. Among men, the significant factors involved in the development of hypertension were age, BMI, and stress level [17].

In our study, among the antihypertensive ingredients, the sodium intake was 4,417 $\pm 2,052$ $\mathrm{mg} / \mathrm{d}$, which when converted to salt constituted on average $11.0 \mathrm{~g} / \mathrm{d}$, potassium: $3,808.5 \pm 1,265.7$ $\mathrm{mg} / \mathrm{d}$, calcium: $724.6 \pm 413.7 \mathrm{mg} / \mathrm{d}$, and magnesium: $383.9 \pm 139.3 \mathrm{mg} / \mathrm{d}$.

In recommendations concerning salt intake, the amount not more than 5-6 g per day is determined, while the average intake in many countries is approx. 9-12 g per day. In the Joint National Committee (JNC) report, it is recommended for patients with hypertension to limit the sodium intake to $2.4 \mathrm{~g}(6 \mathrm{~g} \mathrm{NaCl})$ per day [18]. In our study, it amounted to $11 \mathrm{~g} / \mathrm{d}$. The percentage of people consuming salt in an amount above $6 \mathrm{~g} / \mathrm{d}$ was $97 \%$.

The reduction of salt intake to approx. $5 \mathrm{~g}$ per day contributes to lowering BP by $4-5 \mathrm{~mm} \mathrm{Hg}$ in hypertensive persons and about $1-2 \mathrm{~mm} \mathrm{Hg}$ in normotensive persons [19]. In a landmark study, the International Study of Salt and Blood Pressure (INTERSALT) international research project involving more than 10,000 people aged $20-59$ from 32 countries - it was demonstrated that the difference in sodium intake of $100 \mathrm{mmol}$ per day
$(6 \mathrm{~g} \mathrm{NaCl})$ is associated with the difference of SBP/ /DBP of $6 / 3 \mathrm{~mm} \mathrm{Hg}$ [20].

The consumption of excessive amounts of sodium chloride contributes to the increase of BP, and leads to a variety of metabolic disorders, among others, the weakening of nitric oxide synthetase activity and the reduction of insulin sensitivity [21]. While analyzing the role of sodium in the etiology of hypertension it has been demonstrated that its reduced intake, especially when combined with the application of Dietary Approach to Stop Hypertension (DASH) diet, has a beneficial effect on BP and lipid metabolism, both in healthy individuals as well as in persons with hypertension [22].

In the meta-analysis of studies assessing the impact of the diet low in sodium on BP, it has been shown that in adults the reduction of sodium intake contributes to lowering systolic BP by $3.39 \mathrm{~mm} \mathrm{Hg}$ $(95 \%, 2.46-4.31)$ and diastolic BP by $1.54 \mathrm{~mm} \mathrm{Hg}$ (0.98-2.11). Sodium intake of less than $2 \mathrm{~g}$ per day is conducive to lowering systolic $\mathrm{BP}$ by $3.47 \mathrm{~mm} \mathrm{Hg}$ (0.76-6.18) and diastolic BP by $1.81 \mathrm{~mm} \mathrm{Hg}$ (0.54-3.08) [23].

A diet that includes natural sources of potassium is important in controlling BP because potassium reduces the effects of sodium. The recommended daily intake of potassium for an average adult is about $4,700 \mathrm{mg} /$ day [10]. Potassium supplementation increases the production of nitric oxide in the endothelium and relieves the organ effects of hypertension. It has been observed, however, that in animals, too large intake of sodium and potassium led to cardiac hypertrophy and stroke [24].

There are no precise data defining the dose of potassium as an agent lowering BP. However, the consumption of at least $4.7 \mathrm{~g}(120 \mathrm{mmol} /$ day $)$ demonstrates a very good therapeutic effect. The meta-analysis of Whelton et al. [25] showed that the increase of potassium intake lowers $\mathrm{BP}$ both in patients with and without hypertension. In another meta-analysis, it was demonstrated that increased potassium intake leads to lowering of the SBP by $3.49 \mathrm{~mm} \mathrm{Hg}$ (95\% CI 1.82-5.15) [26].

The influence of calcium and magnesium on BP is ambiguous and not fully understood. It is believed that the impact of calcium on BP is associated with its effect on vascular smooth muscles, Ca-dependent hormones (PTH, 1.25 dihydroxyvitamin D3, calcitonin) activity of reninangiotensin system, the activity of the sympathetic nervous system, metabolism of other electrolytes, calcium-binding proteins, and the concentration 
of free intracellular calcium, whereas the role of other elements in the regulation of $\mathrm{BP}$ value may be largely linked to their influence on calcium metabolism [27]. In the studies, an inverse relationship between the content of potassium, calcium and magnesium in the diet and the BP value is observed $[28,29]$. Meta-analyses show a small reduction of SBP from 0.9 to $1.4 \mathrm{~mm} \mathrm{Hg}$ and DBP from 0.2 to $0.8 \mathrm{~mm} \mathrm{Hg}$ during calcium supplementation (400-2,000 mg/d) [30].

\section{Conclusions}

In summary, in patients with diagnosed hypertension, vast majority of patients have not implemented non-pharmacological methods of hypertension treatment. The most important factors were: excessive weight, including abdominal obesity, low or lack of physical activity, incorrect nutrition (low calcium and potassium intake). High $(97 \%)$ percentage of people who consume excessive amounts of salt has been demonstrated, which is one of the main factors in the development of hypertension. In the healthcare system, there is an urgent need to develop effective methods of education of patients with hypertension. An essential element that would improve the effectiveness of hypertension treatment would be individual work with a nutritionist on the introduction and implementation of non-pharmacological methods of treatment of this disease.

\section{Conflict of interest: None declared}

\section{References}

1. Mancia G, Fagard R, Narkiewicz K et al. [Guidelines ESH/ESC for the management of hypertension in 2013]. Kardiol Pol, 2013; 71: 27-118.

2. Zdrojewski T. [Prevalence and awareness of arterial hypertension in Poland and in the Word]. Postępy Nauk Med, 2011; 3: 4-10.

3. Zdrojewski T, Rutkowski M, Bandosz P et al. Prevalence and control of cardiovascular risk factors in Poland. Assumptions and objectives of the NATPOL 2011 Survey. Kardiol Pol, 2013; 71: 381-392.

4. Broda G, Rywik S. [A multicenter nationwide study of the health of the population - project WOBASZ. Defining the problem and the objectives of the study]. Kardiol Pol, 2005; 63-66.

5. Elmer PJ, Obarzanek E, Vollmer WM. Effects of comprehensive lifestyle modification on diet, weight, physical fitness and blood pressure control: 18-month results of a randomized trial. Ann Intern Med, 2006; 144: 485-495.

6. Szponar L, Wolnicka K, Rychlik E. [Studio photography products and dishes, National Food and Nutrition Institute]. Warsaw 2000.

7. Mancia G, Fagard R, Narkiewicz K at al. The Task Force for the management of arterial hypertension of the European Society of Hypertension (ESH) and of the European Society of Cardiology (ESC). $2013 \mathrm{ESH} / \mathrm{ESC}$ Guidelines for the management of arterial hypertension. Eur Heart J, 2013; 34: 2159-2219.
8. Obesity: Preventing and managing the global epidemic. Report of a WHO consultation. WHO, Geneva 2000; 894.

9. Grundy SM, Brewer HB, Cleeman JI et al. Definition of metabolic syndrome: report of the National Heart, Lung, and Blood Institute/American Heart Association conference on scientific issues related to definition. Arterioscler Thromb Vasc Biol, 2004; 24: $13-18$.

10. Jarosz M ed. [Standards of human nutrition principles of prevention of obesity and non-communicable diseases]. PZWL, Warsaw 2012.

11. Neter JE, Stam BE, Kok FJ. Influence of weight reduction on blood pressure: A meta-analysis of randomized controlled trials. Hypertens, 2003; 42: 878-884.

12. Park HA. The Korea National Health and Nutrition Examination Survey as a Primary Data Source. Korean J Fam Med, 2013; 34: 79 .

13. Després J, Tremblay A, Thériault G et al. Relationships between body fatness, adipose tissue distribution and blood pressure in men and women. J Clin Epi, 1988; 41: 889-897.

14. Grundvold I, Skretteberg PT, Liestol K et al. Upper normal blood pressures predict incident atrial fibrillation in healthy middle-aged men: A 35-year follow-up study. Hypertens, 2012; 59: 198-204.

15. Wenshu L, Zhirong G, Chao $\mathrm{H}$ et al. Interaction of current alcohol consumption and abdominal obesity on hypertension risk. Physiol Behav, 2013; 122: 182-186.

16. Sathish T, Kannan S, Sarma PS et al. Incidence of hypertension and its risk factors in rural Kerala, India: A community-based cohort study. Public Health, 2012; 126: 25-32.

17. Bansal SK, Saxena V, Kandpal SD et al. The prevalence of hypertension and hypertension risk factors in a rural Indian community: A prospective door-to-door study. J Cardiovasc Dis Res, 2012; 3: 117-123.

18. James PA, Oparil S, Carter BL et al. 2014 Evidence-Based Guideline for the Management of High Blood Pressure in AdultsReport From the Panel Members Appointed to the Eighth Joint National Committee (JNC 8). JAMA, 2014; 311: 507-520.

19. Graudal NA, Hubeck-Graudal T, Jürgens G. Effects of LowSodium Diet vs. High-Sodium Diet on Blood Pressure, Renin, Aldosterone, Catecholamines, Cholesterol, and Triglyceride (Cochrane Review) Am J Hypertens, 2012; 25: 1-15.

20. The INTERSALT Co-operative Research Group. Sodium, potassium, body mass, alcohol and blood pressure: The INTERSALT Study. J Hypertens Suppl, 1988; 6: 584-586.

21. Guild SJ, McBryde FD, Malpas SC et al. High dietary salt and angiotensin II chronically increase renal sympathetic nerve activity: A direct telemetric study. Hypertens, 2012; 59: 614-620.

22. Jones DW. Dietary sodium and blood pressure. Hypertens, 2004; 27: 932-935.

23. Aburto NJ, Ziolkovska A, Hooper L et al. Effect of lower sodium intake on health: systematic review and meta-analyses. BMJ, 2013; 346: 1326.

24. Kanbay M, Bayram Y, Solak Y, Sanders PW. Dietary potassium: A key mediator of the cardiovascular response to dietary sodium chloride. J Am Soc Hypertens, 2013; 7: 395-400.

25. Whelton PK, He J, Cutler JA et al. Effects of oral potassium on blood pressure. Meta-analysis of randomized controlled clinical trials. JAMA, 1997; 277: 1624-1632.

26. Aburto NJ, Hanson S, Gutierrez $\mathrm{H}$ et al. Effect of increased potassium intake on cardiovascular risk factors and disease: systematic review and meta-analyses. BMJ, 2013; 346: 1378.

27. Gums JG. Magnesium in cardiovascular and other disorders. Am J Health Syst Pharm, 2004; 61: 1569-1576.

28. Houston MC, Harper KJ. Potassium, magnesium, and calcium: their role in both the cause and treatment of hypertension. J Clin Hypertens, 2008; 10: 3-11.

29. Myers VH, Champagne CM. Nutritional effects on blood pressure. Curr Opin Lipidol, 2007; 18: 20-24.

30. Appel LJ, Giles TD, Black HR at al. ASH position paper: Dietary approaches to lower blood pressure. J Am Soc Hypertens, 2010; 4: 79-89. 